\title{
Determining the Contact of Selected Human Resource Practices on Employee Job Retention in Pizza Max, Karachi
}

\author{
Farhan Zeb*, Nida Zehra and Aqsa Waqil \\ University of Sindh, Jamshoro, Pakistan \\ farhan.zeb@usindh.edu.pk; nida zehra159@yahoo.com; aksawakil1513@gmail.com \\ *Correspondence: $\underline{\text { farhan.zeb@usindh.edu.pk }}$
}

Received: 3rd February 2021; Accepted: 21st April 2021; Published: 1st May 2021

Abstract: Fast food visage amplified challenges with the retention of employees. A newly established fast-food brand in a very short time since its commencement in 2009, Pizza Max has become the top brand name in Karachi even though facing tough and irresistible competition. Due to its extraordinary standards and exceptional service, Pizza Max already has a loyal customer base, and the brand is expanding each day with 8 branches across Karachi already. It also opened its branches in other cities of Pakistan. This research study is intended to getting an understandable and translucent view about employee job retention in diverse Pizza Max branches of Karachi. The prime intention of this research is to determine the contact and the end result of the selected factors on employee job retention in Pizza Max, Karachi. This research study brings a close-deduced representation of selected factors that align with employee retention. All Pizza max branches are tripped for primary data collection. The data was quantitatively collected with the help of survey questionnaires by using the probability random sampling technique. However, the data were analyzed via SPSS, and the outcomes were significant. The main reason for this research is to clarify the association and the result of the selected factors on employee job retention in Pizza Max. At the same time, findings show that the training has no association with employee retention in Pizza Max. However, pay and promotion have greatest association on employee retention in Pizza Max, Karachi. This research will help fast-food organizations enhance employee commitment with the organization along with helping future analysts and researchers.

Keywords: Employee Retention; HR Practices; Herzberg Theory; Pizza Max

\section{Introduction}

Maintaining good culture within an organization is very important for any corporate unit. Organizational culture is an arrangement of communal assumptions, values, and beliefs, which govern how employees act and perform in organizations (Elsbach \& Stigliani, 2018). These communal values have a consequence on the employees in the workplace. When talking about a position of service, the work environment involves the substantial geographical place as well as the instant backdrop of the place of work, such as a production site and administrative center. In general involves other factors linking to the place of service, such as the eminence of the air, noise point, and added perks and remuneration of service. An active working environment for the workforce is the common ambition of all excellent managers. Such a situation has favorable working conditions, sensible management feedback, and consideration of trade goals and priorities.

Farhan Zeb, Nida Zehra and Aqsa Waqil, “Determining the Contact of Selected Human Resource Practices on Employee Job Retention in Pizza Max, Karachi" Annals of Contemporary Developments in Management \& HR (ACDMHR), Print ISSN: 2632-7686, Online ISSN: 2632-7694, pp. 51-57, Vol. 3, No. 2, $1^{\text {st }}$ May 2021, Published by International Association of Educators and Researchers (IAER), DOI: 10.33166/ACDMHR.2021.02.005, Available: http://acdmhr.theiaer.org/archive/v3/v3n2/p5.html. 
The working condition here refers to all subsisting conditions distressing workers in the workplace. The working condition also includes the time period of the job, corporeal aspects, legal privileges and errands. Working condition includes the physical environment in which workers works such as stress and safety on the job. Good work conditions are necessary for employee minds and corporeal interests. Healthy working situations are valuable for employees and organizations. Organizations view as imperative to its undertakings, such as ensure a convenient workload, and promote communication from end to end unfasten office places and usual group meetings. Employees are at liberty to a safe, risk-free environment, whose necessities are enchantment. The current study tried to determine how selected factors have a significant and positive association with employee retention? Moreover, which selected factor has the greatest impact on employee retention?

Training expenditure can be a massive amount depending on the size of the company (Ross et al., 2020). Conversely, the needs of employees are underlined to justify these expenditures because they are supposed to promote employee skills, capabilities, and performance. Training programs attempt to enhance employee skills and add significant knowledge to help them perform better. Training fills the gap between new and old employees in terms of their knowledge, skills and competence. Training is an erudition practice that inquires a moderately lasting change in a person that will advance his/her capability to do their job effectively. The training concerns with programs that advance employee knowledge and expertise improves organizational productivity. Training is usually a short time period process.

Pay and promotion are the finest tools for an organization to conscript and preserve quality workers. Alluring compensation also lends a hand to help the workforce reside and work with motivation on a daily basis in a given job. Compensation packages potentially attract talented workforce that serves the organization with zeal and zest. When deciding amid latent occupation offers, workers over and over again appear to the compensation package first. Various organizations strive to compensate workers to perform better alongside other fringe benefits to encourage them, such as annual tickets, bonuses, profitsharing, healthcare, insurance, etc. This encourages the employees to arrange their efforts in line to the corporate goals. Compensation may also include several monetary and non-monetary incentives. Compensation packages in some businesses also include benefits that extend to their families. The compensation package a business offers to the workforce influences an organization's recruitment swiftness, retention rapidity, and job satisfaction of employees. An organization head should comprehend the substance of compensation and the customary laws to stay behind in the market.

Employees' communication is a practice that an organization uses to successfully handle all relations with workers at the end of the day to attain the goals of the association. The human resources section can play a decisive role in this route. Worker association management has to pay attention to enabling skilled employees to join on representative roles with decision-making responsibilities for their employers. By appealing inputs from equal sides of the employee association, it allows workers to construct quality associations with their co-workers. This can be consummated during the association of informal gettogethers gone from job, by cheering worker relations. Relationships with co-workers that employees establish at the workplace have a significant role in job success and career advancement. Organizations in every corner of the corporate world desire outstanding and energetic employees to increase their performance and productivity. Employees are assets of any organization. This study will help to determine the association of selected factors on employees' retention. This kind of research was not previously done on Pizza Max. This research will also fill the knowledge gap.

\subsection{Underpinning Theory}

According to (Kerlinger, 1979) a theory is a set of interconnected variables, definitions and propositions of a phenomenon among the variables, with amplification a natural occurrence. There are various reasons of employee turnover from the organizational perspective. Chiboiwa (2010) states that 
some of these reasons include practices of recruitment, poor working conditions, low compensation, different styles of management, lack of recognition, job insecurity, job dissatisfaction, lack of promotion, and inadequate training and development opportunities. This study limits the scope to Herzberg two factor theories. Because all the above reasons are included in intrinsic and extrinsic motivational factors.

According to the Two Factor Theory of Frederick, Herzberg individuals are affected by two components. Fulfillment and mental development was a factor of inspiration factors. The disappointment was an aftereffect of cleanliness factors. They do not prompt more significant levels of inspiration; however, there is a disappointment without them. Herzberg's inspiration theory is one of the substance speculations of inspiration. These endeavor to clarify the elements that inspire people by distinguishing and fulfilling their individual necessities and the points sought after to fulfill these longings. This theory of inspiration is known as a two-factor theory. In this study, we are considering an effective strategy to retain employees in an organization. Management must not rely only on intrinsic variables to influence employee retention; but rather combine both intrinsic and extrinsic variables. The dimensions of HR practices are directly or indirectly connected with satisfy/motivate and dissatisfy/hygiene advocate by Herzberg (1959). These factors are known as hygiene factors or dissatisfy and include company policies, salary, co-worker relations, and style of supervision (Steers, 1991). However, removing the causes of dissatisfaction (through hygiene factors) would not result in a state of satisfaction; instead, it would result in a neutral state. As explained later in this study, HR practices of compensation, career development, and work-life balance are grounded on either intrinsic or extrinsic or both.

\section{Literature Review and Research Propositions}

Review of the literature highlight many studies that talk about the work factors that can boost employee retention. Study by Madueke and Emerole (2017) attempted to investigate the role of organizational culture on employee retention in the commercial banking sector and found significant or organizational culture and employee retention. The study reported that when employees see a healthy culture in the business they tend to stay. Leaders have a major responsibility here (Alzyoud et al., 2019) to boost employee retention through indoctrinating the needed factors in the business. In line with this, Deery and Shaw (1999) have also reported that if a business fails to sustain a healthy culture, it results in high employee turnover. In simple, employee retention has heavily dependent on the working culture a business offers to its employees. Case-based research is also available, highlighting employee retention (Jamaluddin et al., 2016). The study has showed that employee retention is a concern and different factors may be used to try and push employees to retain, especially the talented ones.

In addition, training is also found significant in offering significant results in the shape of employee outcomes (Mihardjo et al., 2020; Sangkala et al., 2016). Research studies have reported that when employees are provided with training programs to boost their skills and capabilities, it helps them to further their performance, satisfaction and above all, willingness to stay with the company. Review of the literature in this case underlines many studies across different occupational sectors. Study by Fletcher et al. (2018) found the relationship between training and development and employee retention. The study investigated a mediated model and found that employee training opportunities induce positive attitude towards work which makes employees to remain with the business. The study has reported that making employees to work effectively is an organizational responsibility that can be fulfilled by providing them with ample learning opportunities. This, as a result, pushes them to stay with the company. In addition, studies in the context of Pakistan have also supported this relationship (Aleem \& Bowra, 2020). The authors tested how employee training in the banking sector of Pakistan would enhance employee retention. The study found that employees become connected with the business once they see that the organization invests in their skill and capability building. In sum, these studies confirm the important role of training towards employee 
retention. HR can play an important role in assisting the organization to offer the right set of learning opportunities to ensure the talented employees stay.

The review of literature also supports the notion of compensation and its relationship with employee performance, motivation, satisfaction and retention (AlZgool et al., 2021; Nzyoka \& Orwa, 2016). The literature highlights that employees compensation plan is one of the key factors that makes employees decide to stay or look for another job. Equally, promotion opportunities are also deemed important for employee retention as it is necessary for individuals to see them having career options to grow in the business. Study by Bibi et al. (2017) investigated how compensation and promotional opportunities can influence employee retention and found a significant relationship. The findings concluded compensation plans are a priority for employees in deciding whether to stay or look for another opportunity followed by career growth (promotion) opportunities. in the context of Pakistan, the review of the literature shows similar results. Study by Khan, Aslam and Lodhi (2011) also confirmed the significant relationship between compensation packages and employee retention. In sum, these studies support the correlation of pay and promotion with employee retention, suggesting that when employees are satisfied with the pay and promotion opportunities, it will increase their willingness to stay with the company.

Lastly, communication is also found significant in heightening employee retention. Employee satisfaction with communication in the organization is also an important factor. Tanius et al. (2017) studied and reported a significant relationship between employee satisfaction with communication and their plans to stay with the business. The study also reported that organizational communication policy and procedures have an important role to play which also helps employees to see their organization as a responsible workplace.

\section{Conceptual Framework}

Based on the review of the literature above, the present study investigated the following framework.

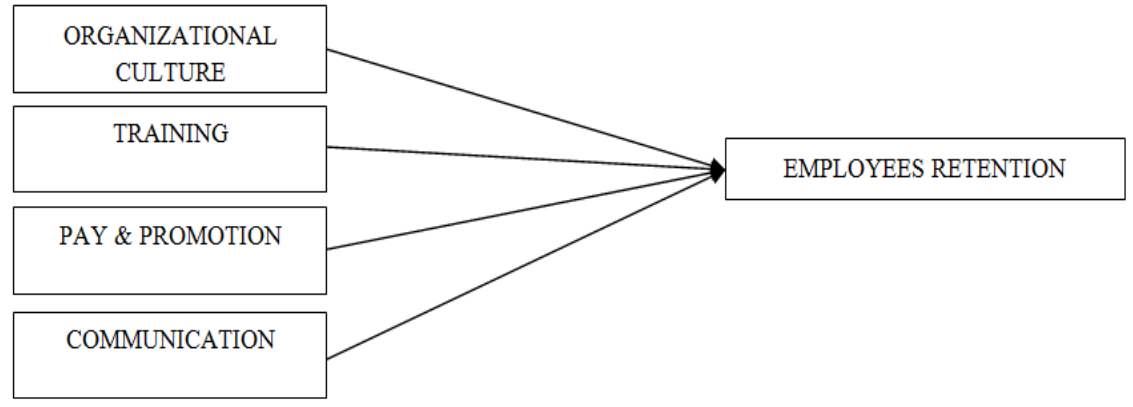

Figure 1. Conceptual Framework

\section{Research Methodology}

This research study brings a close deduced representation of selected factors as imperative factors that align with employee retention. All Pizza max branches are targeted data collection. The data was quantitatively collected with the help of survey questionnaires by using the probability random sampling technique. After data collection, the data was analyzed to decide the relationship between the endogenous and exogenous variables. The total size of the population was 220, and a sample of 140 employees of Pizza Max, Karachi city of Sindh province in Pakistan, was analyzed through SPSS.

\subsection{Data Analysis}

Multiple regression is a statistical approach used to obtain the value of a measure as of various predictor variables on an explanatory variable. It is the instantaneous amalgamation of numerous factors 
to evaluate how and to what level dependent variable affected by various predictor variables. Regression is used to determine the value of a dependent variable based on the value of two or more predictor variables. In this study we checked the impact of selected variables on dependent variable.

Table 1. Model Summary

\begin{tabular}{|c|c|c|c|c|c|c|c|c|c|}
\hline \multirow{2}{*}{$\begin{array}{l}\text { Mo } \\
\text { del }\end{array}$} & \multirow[t]{2}{*}{$\mathbf{R}$} & \multirow{2}{*}{$\begin{array}{c}\mathbf{R} \\
\text { Squar } \\
\mathbf{e}\end{array}$} & \multirow{2}{*}{$\begin{array}{l}\text { Adjusted R } \\
\text { Square }\end{array}$} & \multirow{2}{*}{$\begin{array}{l}\text { Std.Error of } \\
\text { Estimate }\end{array}$} & \multicolumn{5}{|c|}{ Change Statistics } \\
\hline & & & & & $\begin{array}{l}\text { R Square } \\
\text { change }\end{array}$ & F Change & Dff & df2 & Fig. Change \\
\hline 1 & $.807^{a}$ & .599 & .584 & .63088 & .599 & 32.134 & 5 & 161 & .000 \\
\hline
\end{tabular}

Table 2. Anova

\begin{tabular}{|l|l|l|l|l|l|l|}
\hline \multicolumn{2}{|l|}{ Model } & Sum of Squares & Df & Mean Square & F & Sig. \\
\hline \multirow{2}{*}{1} & Regression & 45.282 & 5 & 9.056 & 32.134 & $.000^{\mathrm{b}}$ \\
\cline { 2 - 6 } & Residual & 45.375 & 161 & .282 & & \\
\cline { 2 - 4 } & Total & 166 & & & \\
\hline
\end{tabular}

Table 3. Coefficients

\begin{tabular}{|c|c|c|c|c|c|}
\hline \multirow[t]{2}{*}{ Model } & \multicolumn{2}{|c|}{$\begin{array}{l}\text { Unstandardized } \\
\text { Coefficient }\end{array}$} & \multirow{2}{*}{$\begin{array}{c}\text { Standardized } \\
\text { Coefficient }\end{array}$} & \multirow[t]{2}{*}{$\mathbf{T}$} & \multirow[t]{2}{*}{ Sig } \\
\hline & B & Std. Error & & & \\
\hline 1 (Contant) & 1.832 & .398 & & 4.606 & .000 \\
\hline ORGANIZATIONAL CULTURE & .439 & .084 & .230 & 3.221 & .000 \\
\hline TRAINING & -.032 & .099 & -.022 & -.325 & .745 \\
\hline PAY \& PROMOTION & .437 & .069 & .501 & 6.344 & .000 \\
\hline COMMUNICATION & .283 & .105 & .217 & 2.701 & .008 \\
\hline
\end{tabular}

a. Dependent Variable: Employees' Retention

\section{Findings}

The above table: 1 shows that $58.4 \%$ of employees' retention is explained by all independent variables, such as organizational culture, training, pay and promotion, and communication. Whereas, ANOVA table clearly shows that the model is significant. However, the coefficient table shows that pay and promotion have the greatest impact on employees' retention. While training has no relation with employee retention in Pizza Max. Hence, this study concluded that employees' retention in Pizza Max branches of Karachi. The results discussed in the tables above show that majority of the factors investigated in the present study were significant in their relationship with employee retention, apart from training. The findings suggest that pay and promotion is the most important factor to encourage employees to stay. This finding confirms the results of Bibi et al. (2017) that pay and promotion opportunity play a major part in making employees to stay in business. Furthermore, organizational culture was also found significant in its part towards employee retention. The study supports the findings of Madueke and Emerole (2017) that organizational culture increase retention rates. In addition, the results of the present study also confirm the findings of Tanius et al. (2017) on the role of employees' satisfaction with communication in the organization and their retention rates. 


\subsection{Conclusion}

This study is intended to getting a clear view about organizational culture, training. Pay and promotion \& communication on employee's job retention in diverse Pizza Max branches of Karachi. This research aimed to clarify the association and end result of the selected factors on employee job retention in Pizza Max. Whereas finding shows that training has no association with employee's retention in Pizza Max. However, pay and promotion have the greatest association on employees' retention in Pizza Max, Karachi. This research will help the fast-food organizations to understand how to enhance employee loyalty and retention with the organization. This study will also help future researchers to apply similar models to investigate retention.

\section{References}

Aleem, M., \& Bowra, Z. A. (2020). Role of training \& development on employee retention and organizational commitment in the banking sector of Pakistan. Review of Economics and Development Studies, 6(3), 639-650.

AlZgool, M., Ahmed, U., Shah, S., Alkadash, T., \& AlMaamary, Q. (2021). Going green during COVID-19: Examining the links between green HRM, green supply chain and firm performance in food Industry of Bahrain: The moderating role of lockdown due to COVID-19. Uncertain Supply Chain Management, 9(1), 79-88.

Alzyoud, A. A. Y., Ahmed, U., AlZgool, M. R. H., \& Pahi, M. H. (2019). Leaders' emotional intelligence and employee retention: Mediation of job satisfaction in the hospitality industry. International Journal of Financial Research, 10(3), $1-10$.

Bibi, P., Pangil, F., Johari, J., \& Ahmad, A. (2017). The impact of compensation and promotional opportunities on employee retention in academic institutions: The moderating role of work environment. Journal of Economic $\mathcal{E}$ Management Perspectives, 11(1), 378-391.

Chiboiwa, M. W., Samuel, M. O., \& Chipunza, C. (2010). An examination of employee retention strategy in a private organisation in Zimbabwe. African journal of business management, 4(10), 2103-2109.

Deery, M. A., \& Shaw, R. N. (1999). An investigation of the relationship between employee turnover and organizational culture. Journal of Hospitality \& Tourism Research, 23(4), 387-400.

Elsbach, K. D., \& Stigliani, I. (2018). Design thinking and organizational culture: A review and framework for future research. Journal of Management, 44(6), 2274-2306.

Fletcher, L., Alfes, K., \& Robinson, D. (2018). The relationship between perceived training and development and employee retention: the mediating role of work attitudes. The International Journal of Human Resource Management, 29(18), 2701-2728.

Herzberg, F. (1959). The motivation to work. New York: Holy Wiley \& Sons.

Jamaluddin, N. A., Abdul Majid, A. H., \& Ahmed, U. (2016). Challenges in Attracting Local Workforce in Family Business, In: 2nd International Case Study Conference (ICSC 2017), 30th-31st October 2017, Adya Hotel, Langkawi Island, Kedah, Malaysia.

Kerlinger. (1979). Behavioral research: A conceptual approach. New york: Educational Researcher.

Khan, R. I., Aslam, H. D., \& Lodhi, I. (2011). Compensation Management: A strategic conduit towards achieving employee retention and Job Satisfaction in Banking Sector of Pakistan. International journal of human resource studies, 1(1), 89-97.

Madueke, C. V., \& Emerole, I. C. (2017). Organizational culture and employee retention of selected commercial banks in Anambra State. Saudi Journal of Business and Management Studies, 3(2), 244-252.

Mihardjo, L. W., Jermsittiparsert, K., Ahmed, U., Chankoson, T., \& Hussain, H. I. (2020). Impact of key HR practices (human capital, training and rewards) on service recovery performance with mediating role of employee commitment of the Takaful industry of the Southeast Asian region. Education+ Training, 6(1), 1-21.

Nzyoka, C. M., \& Orwa, B. H. (2016). The relationship between Total compensation and employee performance in the insurance industry, case of Mayfair insurance company limited. Psychology and Behavioral Sciences, 5(1), 20-36.

Ross, A. J., MacGregor, R. G., Zihindula, G., \& Chola, L. (2020). The training of healthcare professionals: An expense or an investment?. South African Medical Journal, 110(5), 369-373.

Sangkala, M., Ahmed, U., \& Pahi, H. M. (2016). Empirical investigating on the role of supervisor support, job clarity, employee training and performance appraisal in addressing job satisfaction of nurses. International Business Management, 10(23), 5481-5486. 
Steers, R. M. (1991). Motivation and work behavior (5th ed.).

Tanius, E., Pheng, L. S., Kasim, C. M. M., \& Yulia, A. (2017). The relationship between communication satisfaction and procedural justice with employee retention. AGE, 29(2), 421-424.

Uddin, M. H. (2013). Role of transformational leadership in organizational change: mediating role of trust. Journal of Business and Management, 7(2), 72-76.

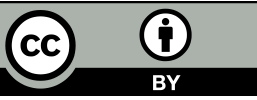

(C) 2021 by the author(s). Published by Annals of Contemporary Developments in Management \& HR (ACDMHR), under the terms and conditions of the Creative Commons Attribution (CC BY) license which can be accessed at http://creativecommons.org/licenses/by/4.0. 